\title{
The intensity of the geomagnetic field in the late-Archaean: new measurements and an analysis of the updated IAGA palaeointensity database
}

\author{
Andrew J. Biggin, Geert H. M. A. Strik, and Cor G. Langereis \\ Palaeomagnetic Laboratory 'Fort Hoofddijk', Utrecht University, Budapestlaan 17, 3584 CD Utrecht, The Netherlands
}

(Received October 16, 2007; Revised May 23, 2008; Accepted July 6, 2008; Online published January 23, 2009)

\begin{abstract}
We firstly present the results of a detailed palaeointensity study performed on 54 samples from 9 volcanic units of late Archaean age (2724-2772 Ma) from the Pilbara Craton, Western Australia. These results were severely affected by magnetomineralogical alteration occurring during the laboratory heating process necessitating the application of a correction procedure. The correction allowed results from three lavas to pass strict selection criteria but we deem that only one of these exhibits sufficient internal consistency to be considered moderately reliable. It yields a virtual dipole moment of $47 \pm 6 \mathrm{ZAm}^{2}$ which is $60 \%$ of the present-day value. We combine this determination with a filtered dataset from the updated IAGA (International Association of Geomagnetism and Aeronomy) palaeointensity database, PINT08. Directional secular variation has recently been shown to have changed fundamentally since the Archaean, probably as a consequence of inner core growth since that time. However, here we argue that it is still unclear whether this evolution was accompanied by a single long timescale change in average poloidal field intensity. While the distribution of Precambrian palaeointensity determinations as a whole is significantly lower than that for the last $300 \mathrm{Myr}$, we show that this finding largely reflects data from the Proterozoic aeon. The distribution of more ancient measurements from the late Archaean-earliest Proterozoic is indistinguishable from that of the last $300 \mathrm{Myr}$ which might suggest that a 'Proterozoic dipole low' period existed between two periods of higher field intensity. Were this pattern of long-term geomagnetic intensity variation to be supported by the addition of new data in the future, then it could indicate a related three-stage evolution in core dynamics, namely: vigorous thermal convection caused by high core-mantle heat flux early in the Earth's history, weaker thermal convection later as the heat flux fell, and finally, strong compositional convection since the inner core nucleated.
\end{abstract}

Key words: Palaeointensity, Archaean, Pilbara, magnetomineralogical alteration, inner core growth.

\section{Introduction}

Geomagnetic field behaviour varies on timescales much longer than those associated with outer core convection. Observed variations in average reversal rate with a time period of approximately $200 \mathrm{Myr}$ (Courtillot and Olson, 2007) were most likely forced by mantle convection and resulting changes in the net heat flux across the core-mantle boundary and/or the spatial pattern of this heat flux. Longer timescale variations in geomagnetic behaviour (Macouin et al., 2004; Coe and Glatzmaier, 2006; Biggin et al., 2008) may well be associated with the growth of the inner core which affects the geodynamo both by changing the geometry of the spherical shell it operates in and by providing a highly efficient power source (Gubbins et al., 2003; Labrosse, 2003) for its operation.

Smirnov and Tarduno (2004) studied geomagnetic palaeosecular variation (PSV) in the late Archaean and early Proterozoic and reported that it was similar to that observed in the last 5 Myr with a suggestion of more dipole dominance. Very recently, Biggin et al. (2008) reanalysed PSV in this period (2446-2823 Ma) with a much larger

Copyright (c) The Society of Geomagnetism and Earth, Planetary and Space Sciences (SGEPSS); The Seismological Society of Japan; The Volcanological Society of Japan; The Geodetic Society of Japan; The Japanese Society for Planetary Sciences; TERRAPUB. and more strictly filtered dataset and concluded that it was fundamentally different during the late Archaean and early Proterozoic relative to more recent times (both the period 0-5 Ma and the period 0-195 Ma). They argued that, consistent with some dynamo simulations (Roberts and Glatzmaier, 2001; Coe and Glatzmaier, 2006), this was probably due to the growth of the inner core between these periods acting to destabilise the geodynamo by changing the geometry of the outer core.

This fundamental shift in secular variation style may have been accompanied by a increasing tendency for polarity reversal in more recent times (see discussions by Roberts and Piper, 1989; Dunlop and Yu, 2004; Coe and Glatzmaier, 2006; Biggin et al., 2008) but was it also accompanied by a fundamental change in mean field intensity?

The inner core has almost certainly increased substantially in size over the period of time for which absolute palaeointensity determinations are potentially available (the last 3200 Myr at least) and most probably begun forming during this period. The determining factor for the age of the inner core and the rate of its subsequent growth is the heat flux across the core-mantle boundary. All else being equal, the nucleation of the inner core is expected to have significantly increased the power available for Ohmic dissipation in the outer core by allowing the initiation of compositional 


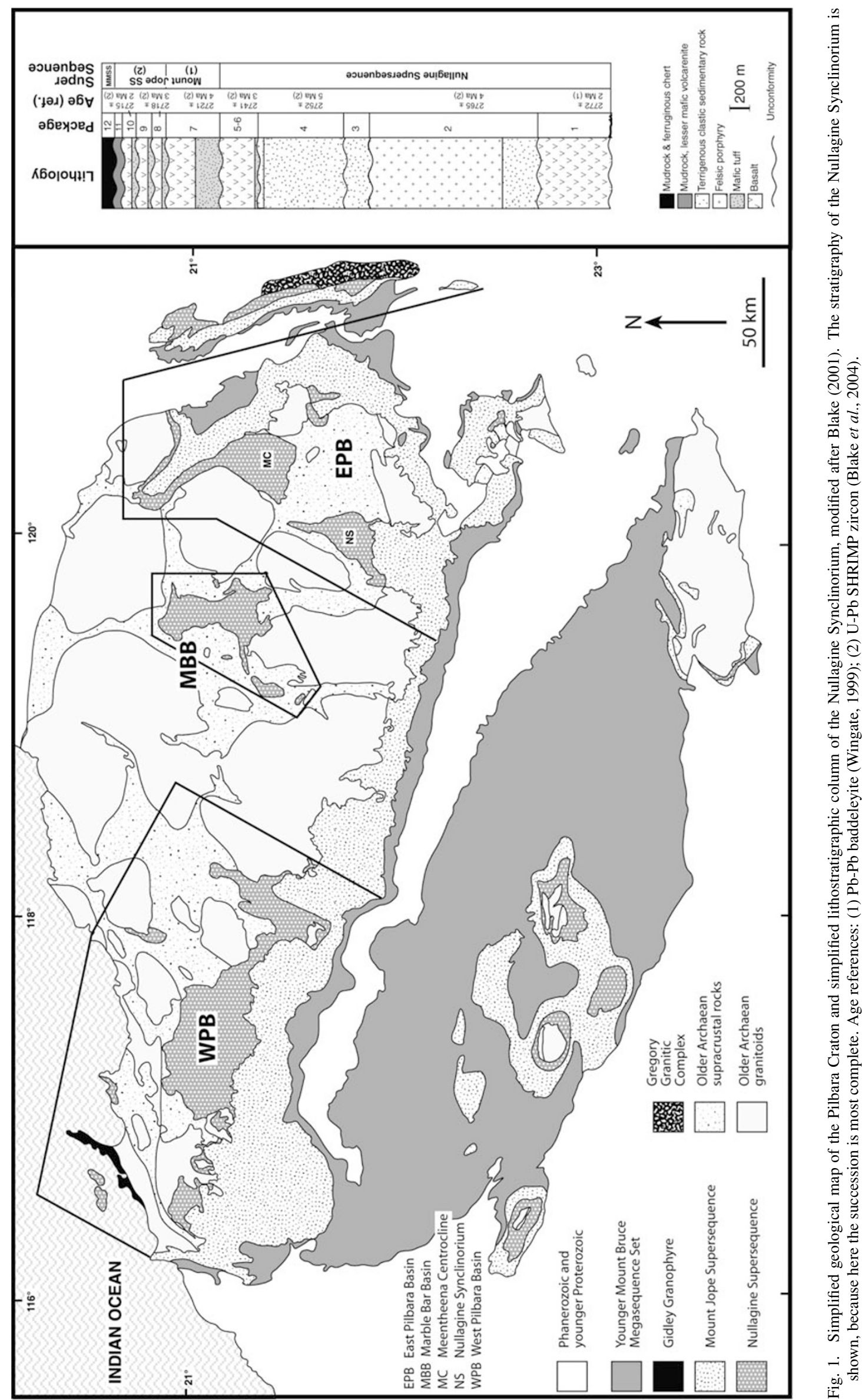


Table 1. Summary of mean directional data from sites used in the palaeointensity study. AMG refers to Australia Map Grid, $N$ is the number of samples measured, $n$ is the number of sample directions used for the mean direction, Plat is the implied palaeolatitude.

\begin{tabular}{|c|c|c|c|c|c|c|c|c|c|c|c|c|c|c|}
\hline Package & $\begin{array}{c}\text { Site } \\
\text { Number }\end{array}$ & Lithology & $\begin{array}{l}\text { AMG coordinates } \\
\text { (AGD 84) }\end{array}$ & Strike/Dip & $\mathbf{N}$ & $\mathbf{n}$ & $\mathrm{dec}^{\circ}$ & inc $^{\circ}$ & k & $\alpha 95^{\circ}$ & $\mathbf{R}$ & Plat $^{\circ}$ & $\begin{array}{l}\text { VGP } \\
\text { lat }^{\circ}\end{array}$ & $\begin{array}{l}\text { VGP } \\
\text { long }\end{array}$ \\
\hline 1 & GSP66 & asalt & $51 \mathrm{~K} 0212666-7628329$ & $345 / 26 \mathrm{E}$ & 7 & 7 & $\overline{42.1}$ & 71.5 & 4898.0 & 0.9 & 6.999 & 56.2 & -45.4 & 149.4 \\
\hline 1 & GSP65 & $\pi$ & 51K 0212666 - & $5 / 26 E$ & 7 & 6 & 136.6 & 67.2 & 748.0 & 2.5 & 5.993 & 49.9 & -45.6 & 159.5 \\
\hline 1 & GSP63 & isalt & $51 \mathrm{~K} 02126$ & $345 / 28 \mathrm{E}$ & 7 & 7 & 129.1 & 70.5 & 161.5 & 4.8 & 6.963 & 54.7 & -39.6 & 155.8 \\
\hline 1 & GSP62 & asalt & $51 \mathrm{~K} 0212600-7628194$ & $345 / 28 \mathrm{E}$ & 7 & 6 & 132.9 & 70.4 & 175.6 & 5.1 & 5.972 & 54.5 & -41.7 & 154.9 \\
\hline 1 & GSP61 & Basalt & $51 \mathrm{~K} 0212600-7628194$ & $345 / 28 \mathrm{E}$ & 7 & 7 & 129.4 & 66.5 & 1014.7 & 1.9 & 6.994 & 49.0 & -41.6 & 162.9 \\
\hline 7 & GSP79 & Basalt & 51K $0228781-7639463$ & 023/15 E & 10 & 10 & 151.8 & 64.2 & 589.2 & 2.0 & 9.985 & 46.0 & -56.3 & 156.7 \\
\hline 7 & GSP78 & Basalt & $51 \mathrm{~K} 0228667-7639456$ & 023/15 E & 14 & 12 & 160.8 & 64.9 & 440.5 & 2.1 & 11.975 & 46.9 & -60.1 & 147.2 \\
\hline 7 & GSP77 & Basalt & 51K $0228554-7639452$ & $023 / 13 \mathrm{E}$ & 14 & 11 & 164.1 & 63.3 & 15.6 & 11.9 & 10.358 & 44.8 & -63.1 & 145.8 \\
\hline 2 & GSP91 & Massive dacite porphyry & $51 \mathrm{~K} 0226052-7650595$ & $040 / 20 \mathrm{E}$ & 10 & 10 & 292.6 & -48.9 & 164.7 & 3.8 & 9.945 & 29.8 & 29.4 & 7.2 \\
\hline
\end{tabular}

convection (Buffett, 2003; Labrosse, 2003). This process also releases latent heat which further helps drive convection. We might therefore expect Precambrian palaeointensity measurements to provide a 'smoking gun' signature for the onset of inner core growth by recording a marked increase in their values.

Some reviews of Precambrian palaeointensity (e.g. Prévot and Perrin, 1992; Smirnov et al., 2003; Dunlop and $\mathrm{Yu}, 2004)$ have concluded that there is little evidence for any long term trend in mean geomagnetic intensity. Conversely, Macouin et al. (2004) argued for a long-term increase of dipole moment and in particular, a 'significant increase' initiated some time between 1000 and $300 \mathrm{Ma}$.

This is consistent with recent studies of the lowermost mantle (Lay et al., 2006; van der Hilst et al., 2007) which concluded that the present day heat flux across the CMB is rather high $(\sim 10 \mathrm{TW})$ which, extrapolated to earlier periods, would have resulted in the inner core forming relatively late in the Earth's history (in, say, the last 1.5 billion years).

Here we aim to better constrain the evolution in mean geomagnetic intensity since the Archaean. We firstly report on a palaeointensity study performed on late Archaean lavas from the Nullagine and Mount Jope Supersequences, Pilbara Craton, Western Australia. Secondly, we combine the most reliable determination obtained from this study with others from the same period (taken from the newly updated PINT08 database) and compare these with younger estimates in an effort to ascertain the effect of inner core nucleation/growth on the evolution of the geomagnetic dipole moment over the last few billions of years.

\section{Geology and Sampling}

The geology of the Nullagine and Mount Jope Supersequences is described in detail by Blake (1993, 2001). The two supersequences are interpreted as the rock record of two phases of continental break-up. The first phase is marked by the extrusion of large volumes of subaerial flood basalts, followed by development of extensional sedimentary basins and associated felsic and mafic volcanics. The second phase is associated with mafic and minor felsic volcanism (Fig. 1). The Nullagine and Mount Jope Supersequences have been subdivided into 12 Packages in the Nullagine Synclinorium (Fig. 1), based on regional unconformities (Blake, 2001). These Packages are provisionally numbered from 1 to 12 until their full regional extent is known. A regional correlation is currently in progress (Blake, in prep.) and recent palaeomagnetic work (Strik et al., 2003; Strik, 2004) seems to confirm the stratigraphic framework. The Nullagine and Mount Jope Supersequences have recently been dated with high precision (Fig. 1, Wingate, 1999; Blake et al., 2004). The succession is generally only gently folded and the metamorphic grade does not exceed $200 \mathrm{MPa}$ and $300^{\circ} \mathrm{C}$ (Smith et al., 1982).

The samples used for palaeointensity determination were flood basalts and a felsic porphyry (see Section 4.2) taken from the Meentheena Centrocline in the East Pilbara Basin (Fig. 1). Rock core samples were initially collected for NRM analysis (Strik et al., 2003; Strik, 2004) during trips in 1999 and 2000, and the most promising specimens of these rock core samples were selected for palaeointensity determination. For this study, we selected flood basalt specimens from Package 1 (GSP61-63, 65, and 66); felsic porphyry samples from Package 2 (GSP91); and flood basalt samples from Package 7 (GSP77-79). Published ages of these packages made using the SHRIMP $\mathrm{U}-\mathrm{Pb}$ and $\mathrm{Pb}-\mathrm{Pb}$ methods (Wingate, 1999; Blake et al., 2004) range from $2772 \pm 2 \mathrm{Ma}$ (Package 1) to $2721 \pm 4 \mathrm{Ma}$ (Package 7).

Careful bedding plane measurements were made at the outcrops. The tectonic corrections resulting from these tended to be small (Table 1) as the folding of these flood basalts was generally slight. Core samples were generally taken in the field using a petrol engine drill and orientated with both a magnetic and sun compass; a few hand samples were also collected. The sampling sites were carefully selected outcrops that were recently exposed in incised river valleys; the sampled material was therefore extremely fresh. In the laboratory, the hand specimens were cored and all cores were cut to standard specimens of $22 \mathrm{~mm}$ length.

\section{Methodology}

For the directional study, one specimen from each core was stepwise demagnetised. This was most commonly done using thermal demagnetisation carried out in a magnetically shielded, laboratory-built furnace although alternating field (AF) demagnetisation was also performed in some cases. The NRM was measured using a $2 \mathrm{G}$ Enterprises DCSQUID cryogenic magnetometer or occasionally using an AGICO JR5 spinner magnetometer.

NRM directions were analysed and interpreted with $\mathrm{Zi}$ jderveld diagrams (Zijderveld, 1967). Principal component analysis (Kirschvink, 1980) was used to determine the directions of the various NRM components. No directions with a maximum angular deviation (MAD) greater than $10^{\circ}$ were used. 

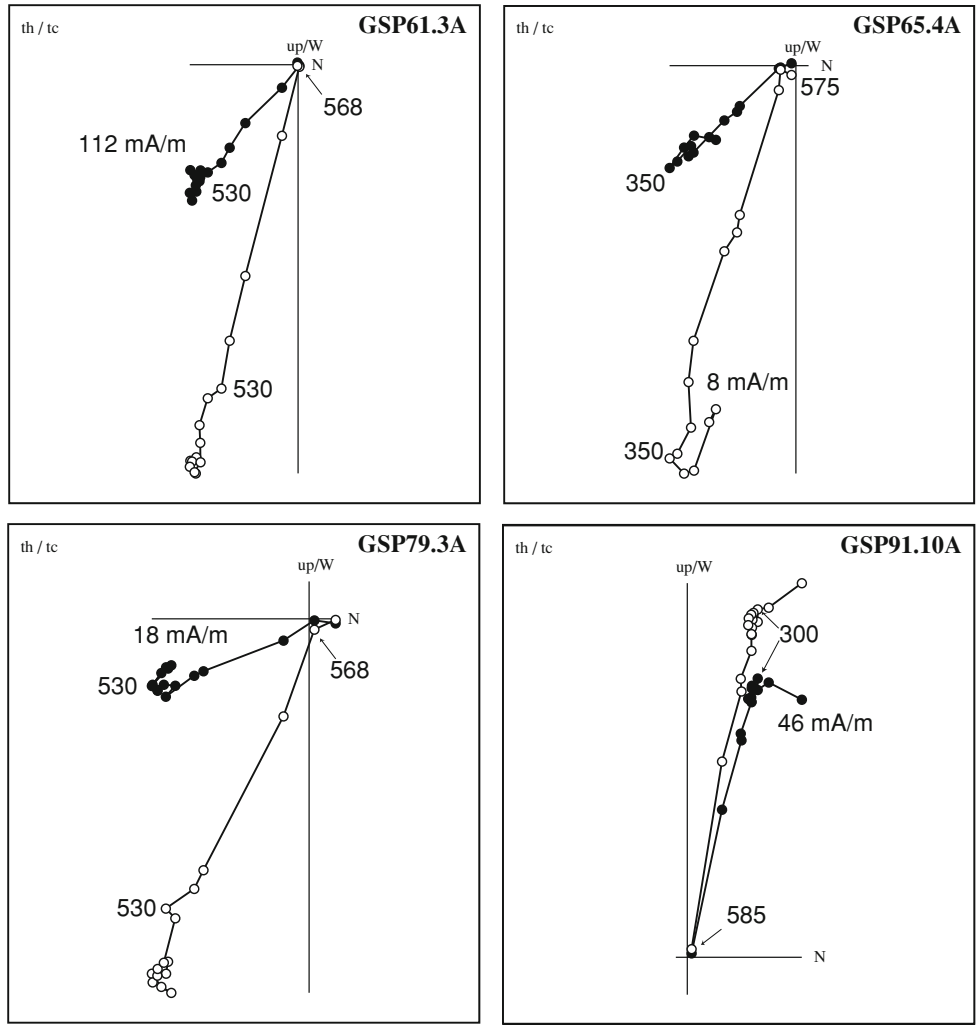

Fig. 2. Representative Zijderveld plots from samples from the same units as measured in the palaeointensity experiments. Filled (unfilled) points represent the horizontal (vertical) component. Numbers represent the temperature (in degrees Celsius) of the thermal demagnetisation treatment. The intensity of the untreated NRM is also given.

A modified horizontal translation Curie balance that applies a cyclic field (Mullender et al., 1993) was used to ascertain the magnetomineralogy of samples and their propensity to alter in the palaeointensity experiments. Small amounts of material (60 to $120 \mathrm{mg}$ ) were crushed to a coarse powder and subjected to a number of heatingcooling cycles during which the magnetic field fluctuated between 150 and $300 \mathrm{mT}$. The total magnetic moment of the samples was measured every 10 seconds. Samples were first heated to $450^{\circ} \mathrm{C}$, maintained at the set point for $10 \mathrm{~min}$ utes and cooled down to $350^{\circ} \mathrm{C}$. The cycle was repeated for $480,510,540$ and $570^{\circ} \mathrm{C}$, each time leaving the sample for 10 minutes at the set point and subsequently cooled down to $100^{\circ} \mathrm{C}$ less. A final heating step to $600^{\circ} \mathrm{C}$ was carried out, after which the sample was cooled down to room temperature.

The palaeointensity experiments themselves were undertaken at Scripps Institution of Oceanography in late 2003 and employed the IZZI variant (Tauxe and Staudigel, 2004) of the Thelliers' (1959) method incorporating pTRM checks for alteration and pTRM tail checks for MD behaviour (Riisager and Riisager, 2001). The intensity of the laboratory field applied in the experiments was $20 \mu \mathrm{T}$ and this was directed along the $z$ axis of the samples. Nineteen temperature steps were chosen between 250 and $575^{\circ} \mathrm{C}$ and above $520^{\circ} \mathrm{C}$, these were separated by just $5^{\circ} \mathrm{C}$. The results of the palaeointensity experiments were analysed using Arai plots (Nagata et al., 1963) and parameters developed by Coe et al. (1978) and Selkin and Tauxe (2000).

\section{Results}

\subsection{Palaeodirectional and rock magnetic results}

Detailed descriptions of the extensive measurements of palaeomagnetic directions made using rocks from the Nullagine and Mount Jope Supersequences are given elsewhere (Strik et al., 2003; Strik, 2004). Here, we present results only from the subsection of sites which were studied for palaeointensity purposes. Samples from these tended to be dominated by their characteristic components of remanence (ChRM) which was generally isolated above $350^{\circ} \mathrm{C}$ (Fig. 2). Unlike samples from some other sites from this area (Strik et al., 2003; Strik, 2004), they did not display strong and well-developed low and medium temperature components. Table 1 summarises the relevant directional data and indicates that, with one exception (GSP77), within-site consistency of directions was high. All of the units sampled in Package 2 and several sampled in Package 7 were reversely magnetised with respect to the other units in the studied sequence. Their ChRMs passed the reversal test (Strik et al., 2003; Strik, 2004) suggesting that they were primary components of remanence and that secular variation was averaged. Furthermore, a fold test was passed in the Nullagine Supersequence units predating those studied here (Strik, 2004).

The remanent magnetisation of all basaltic rocks from the Pilbara region is, on average, several orders of magnitude weaker than that of most basalts of Phanerozoic age. Very low remanence intensities were also found in pristine basalts of the Kaapvaal craton (Strik et al., 2007) and most likely reflect a different bulk chemistry of basalts formed 

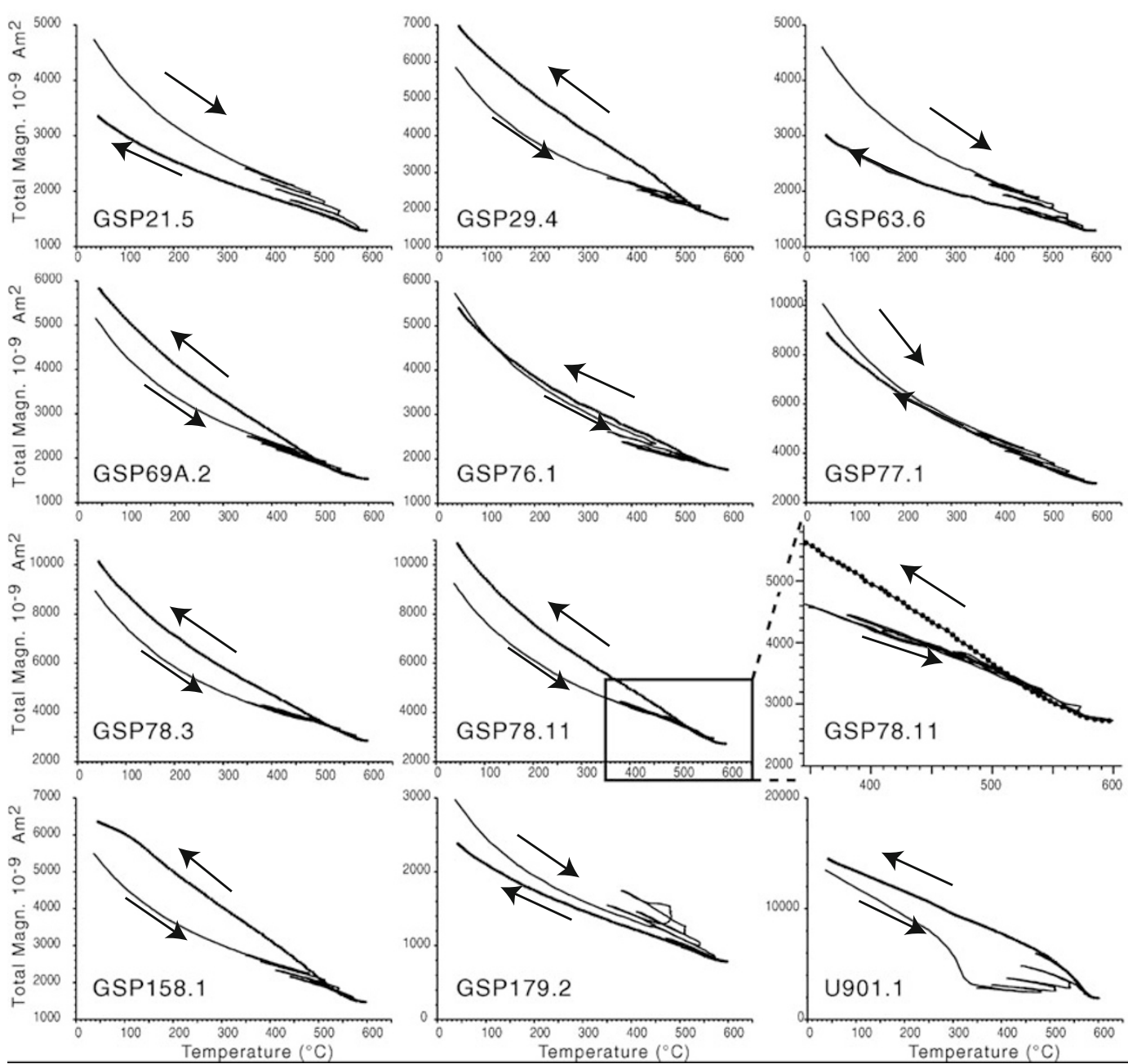

Fig. 3. Diagrams of total magnetisation versus temperature of selected samples measured on the Curie balance. Arrows indicate heating and cooling curves. Note that set point temperatures were maintained for 10 minutes and in some cases, this led to a progression of alteration.

at this time. These low intensities allowed the paramagnetic component to feature strongly in the thermomagnetic curves measured from these samples (Fig. 3). To isolate the ferromagnetic behaviour, the paramagnetic moment was subtracted from the total magnetic moment. To do this, first the specific (mass dependent) paramagnetic and diamagnetic susceptibilities were determined, using least square fitting. The susceptibility is proportional to the inverse of the temperature, according to the Curie-Weiss law. The total paramagnetic moment is calculated by multiplying the specific paramagnetic susceptibility by the applied field. Subsequently, the result is subtracted from the total magnetic moment, which gives the total ferromagnetic (sensu lato) moment. The resulting plots are shown in Fig. 4 and show alteration much more clearly than those displaying the total magnetisation. This alteration frequently takes the form of an enhanced ferromagnetic moment on the cooling curve which potentially reflects the formation of new magnetite grains from clay minerals in the groundmass of the samples (Cottrell and Tarduno, 2000). However, we point out that this process was limited in absolute terms: the thermomagnetic curves remained dominantly paramagnetic and the samples were not visibly weathered (Section 2).

The thermomagnetic curves shown in Fig. 4 display
Curie temperatures close to that of pure magnetite $\left(580^{\circ} \mathrm{C}\right)$ which is consistent with the unblocking temperature spectra observed in the directional experiments. Ti-poor titanomagnetite is the most common ferrimagnetic mineral in subaerial basalts where it is generally produced by deuteric oxidation of a primary Ti-rich phase. Its presence in these samples, when taken together with the demonstrably primary nature of their directions of remanence, implies that their permanent magnetisation may well be a thermoremanent magnetisation (TRM) as required for accurate absolute palaeointensity measurements.

\subsection{Palaeointensity results}

Based on the outcome of the Curie balance measurements, Package 7 sites GSP77-79 were chosen for palaeointensity determination, as samples from these sites show the least alteration. Samples of Package 1 sites GSP61-63, 65 and 66 sometimes showed alteration starting at $480^{\circ} \mathrm{C}$, but were chosen as the next best target. Package 2 samples from site GSP91 showed clear alteration, but were included to test the preselection method.

A total of 54 samples were measured in the palaeointensity experiment but these were all strongly affected by alteration beginning around $500^{\circ} \mathrm{C}$ which, in most cases, dramatically increased the capacity of the sample to acquire 


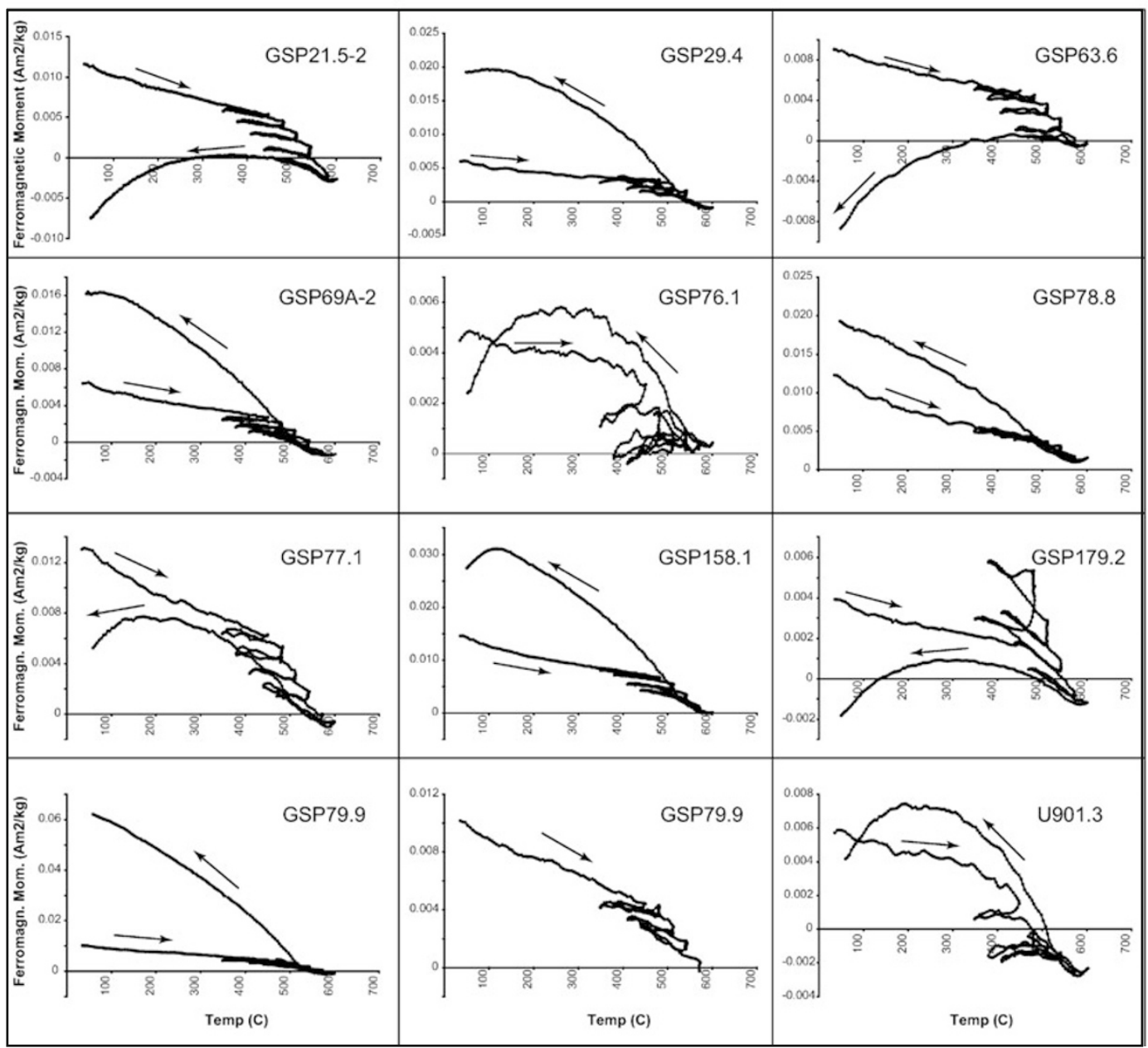

Fig. 4. Diagrams of the total ferrimagnetic moment versus temperature of selected samples calculated from Curie balance measurements. Arrows indicate heating and cooling curves.

magnetisation. This was readily apparent from the highly concave shape of the Arai plots and/or the failing pTRM checks (left column of Fig. 5).

Many of the samples we measured had only very small overprints but despite this, their unblocking temperature spectra were generally such that the primary magnetisation was barely reached before the occurrence of alteration. In the case of a few samples, it was possible to obtain palaeointensity estimates which had low technical quality (low quality and fraction parameters-see Coe et al., 1978) and which may have still been affected by incipient alteration. However, instead of using these potentially biased measurements we decided to attempt to correct for the alteration in all samples using the basic method outlined by Valet et al. (1996) and McClelland and Briden (1996).

This alteration correction works by shifting points on the Arai plot along the TRM axis (the abscissa) according to the cumulative net discrepancy observed in the pTRM checks up to that point. Only points on an Arai plot which have an associated pTRM check may be corrected for the effects of alteration. In this experiment, pTRM checks were only made after every alternate temperature step which implied that only half the points on the Arai plot could be used to produce the palaeointensity estimate. Fortunately, the original experiments were rather intensive which meant that there were still sufficient numbers of points remaining with which to obtain the estimate. Also, because each pTRM check was performed to the temperature of the doubleheating step at which the previous pTRM check was made, all the information required to reliably make the alteration correction was, in principle (see below), available.

One requirement for the alteration correction method to work properly is that the samples strictly obey Thellier's (1938) laws of thermoremanence. This is because, in palaeointensity experiments where samples do not behave in a strictly single-domain manner with respect to pTRM acquistion, pTRM checks can fail despite the absence of any alteration (Biggin and Thomas, 2003b). To ensure this was not the case here, we analysed the results of the pTRM tail checks and used the strict criteria outlined for 'Class A' results by Leonhardt et al. (2004) to exclude any samples which may be subject to MD behaviour. Leonhardt et al. estimate the magnitude of the imparted pTRM tail using a parameter called $t^{*}$ which takes the intensity and direction of the applied field relative to the NRM into account. This is required to be less than $3 \%$ of the full pTRM; they also calculate the relative difference between the measurement made after a standard demagnetisation step and that made after a pTRM tail check step at the same temperature $(\delta(T R))$ and require this to be less than $10 \%$. 
(a) Samples failing due to clear zigzagging behaviour

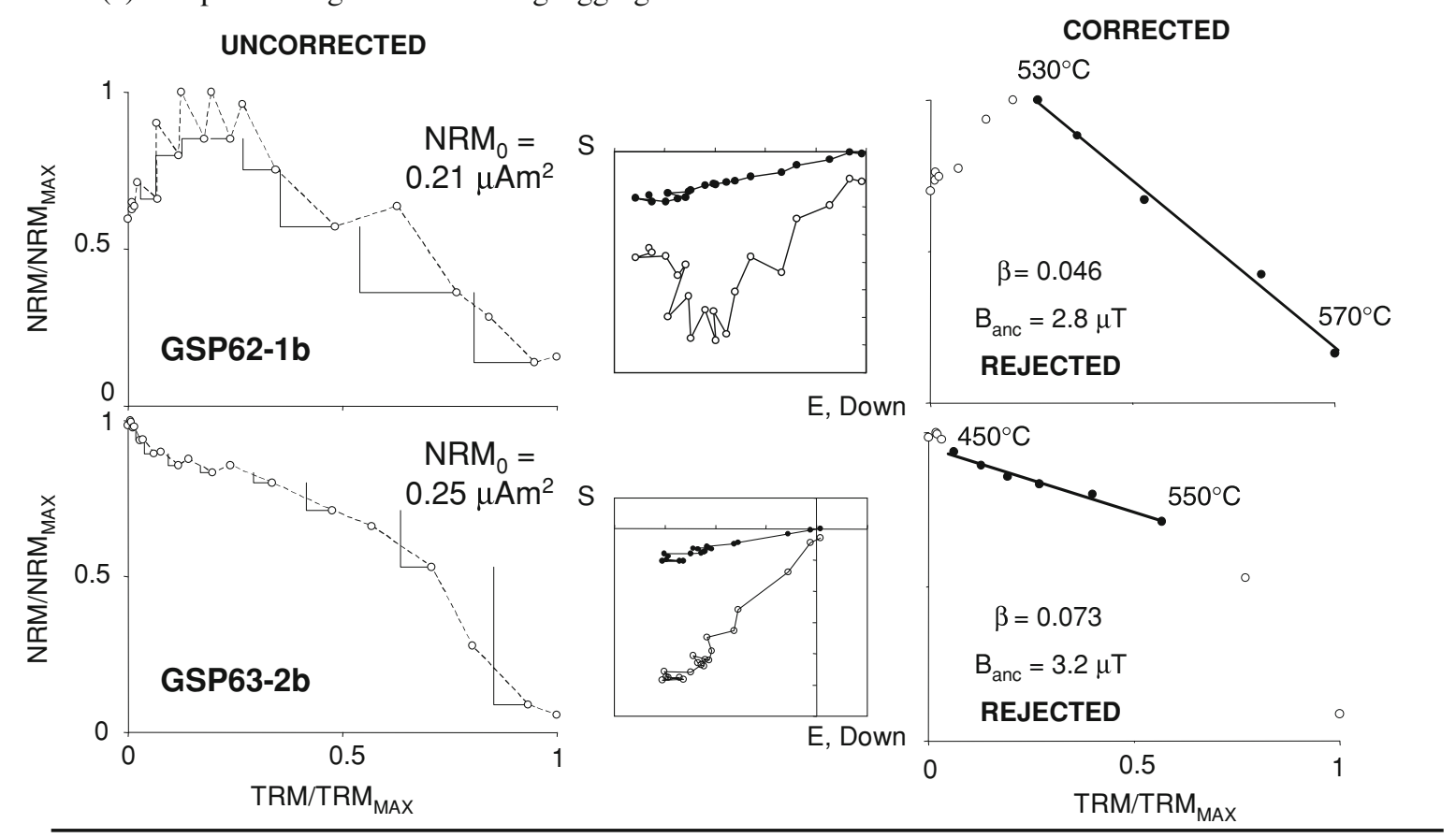

(b) Samples failing due to $\beta>0.035$

UNCORRECTED

CORRECTED
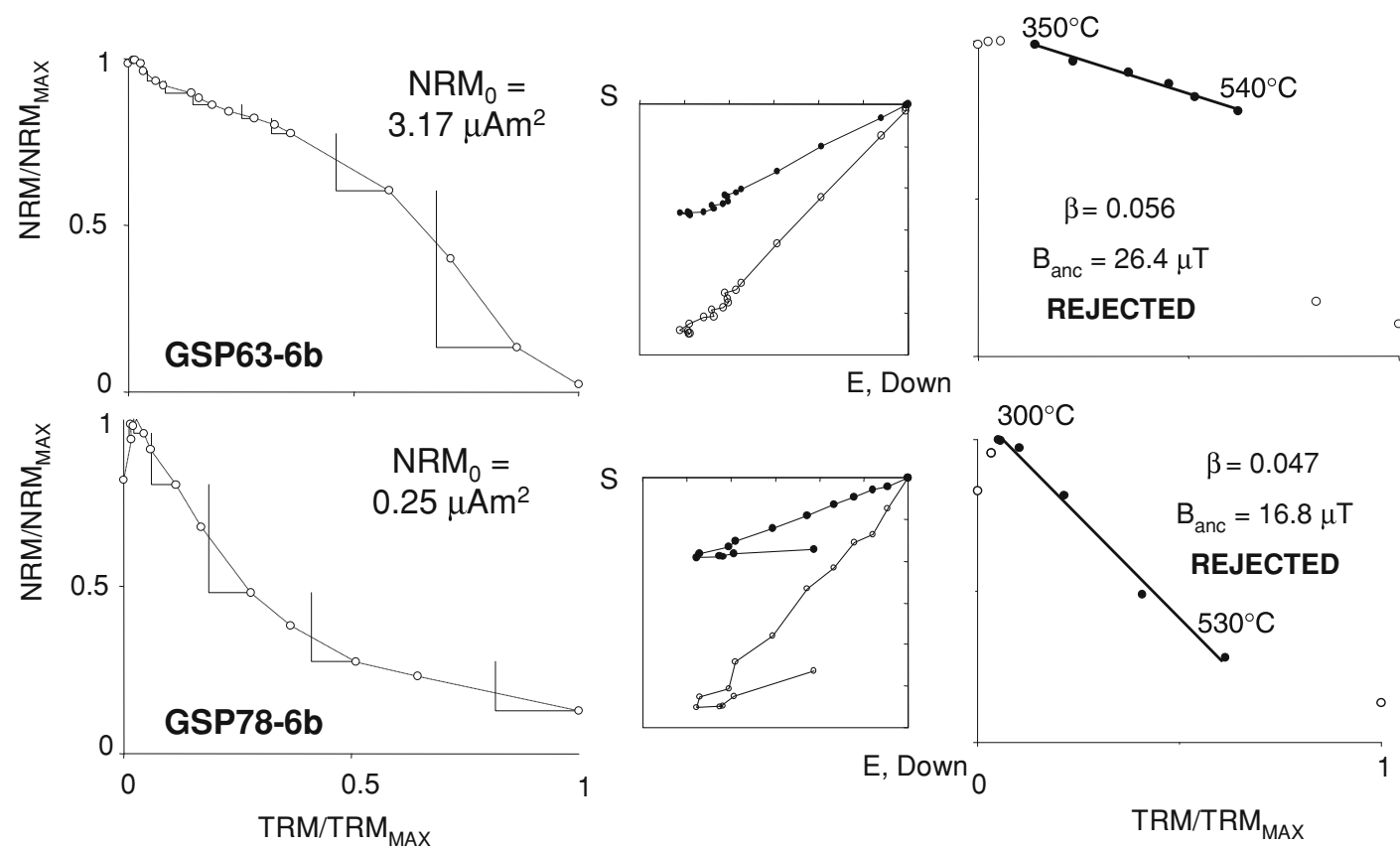

Fig. 5. Examples of rejected (a, b) and accepted (c, d) palaeointensity measurements. Arai plots before (left) and after (right) correction for alteration are given and the associated Zijdeveld plots are shown in the centre (filled points—horizontal component, unfilled points-vertical component).

Another requirement for the correction method to work properly is that the alteration which does occur during the experiment affects only remanence carriers with (un)blocking temperatures below that of the temperature to which the pTRM checks are made. For example, in order to use a pTRM check made between $500^{\circ} \mathrm{C}$ and $20^{\circ} \mathrm{C}$ to correct a point on the Arai plot associated with a temperature higher than $500^{\circ} \mathrm{C}$ (say $520^{\circ} \mathrm{C}$ ), it is necessary that all the alteration that which had taken place before the check was measured had affected only remanence carriers with block- ing temperatures less than $500^{\circ} \mathrm{C}$. The pTRM tail check criteria discussed above provide some protection against this problem: in addition to indicating non-SD remanence, they can also detect chemical remanent magnetisation (CRM) imparted to new remanence carriers with blocking temperatures above the temperature of the check. A further (highly sensitive) check was also made by examining the complete Arai plots (and Zijdeveld plots) for signs of zigzagging. Those points which were produced by IZ double heating steps (in which the remagnetisation were performed before 
(c) Samples passing criteria but displaying some zigzagging behaviour
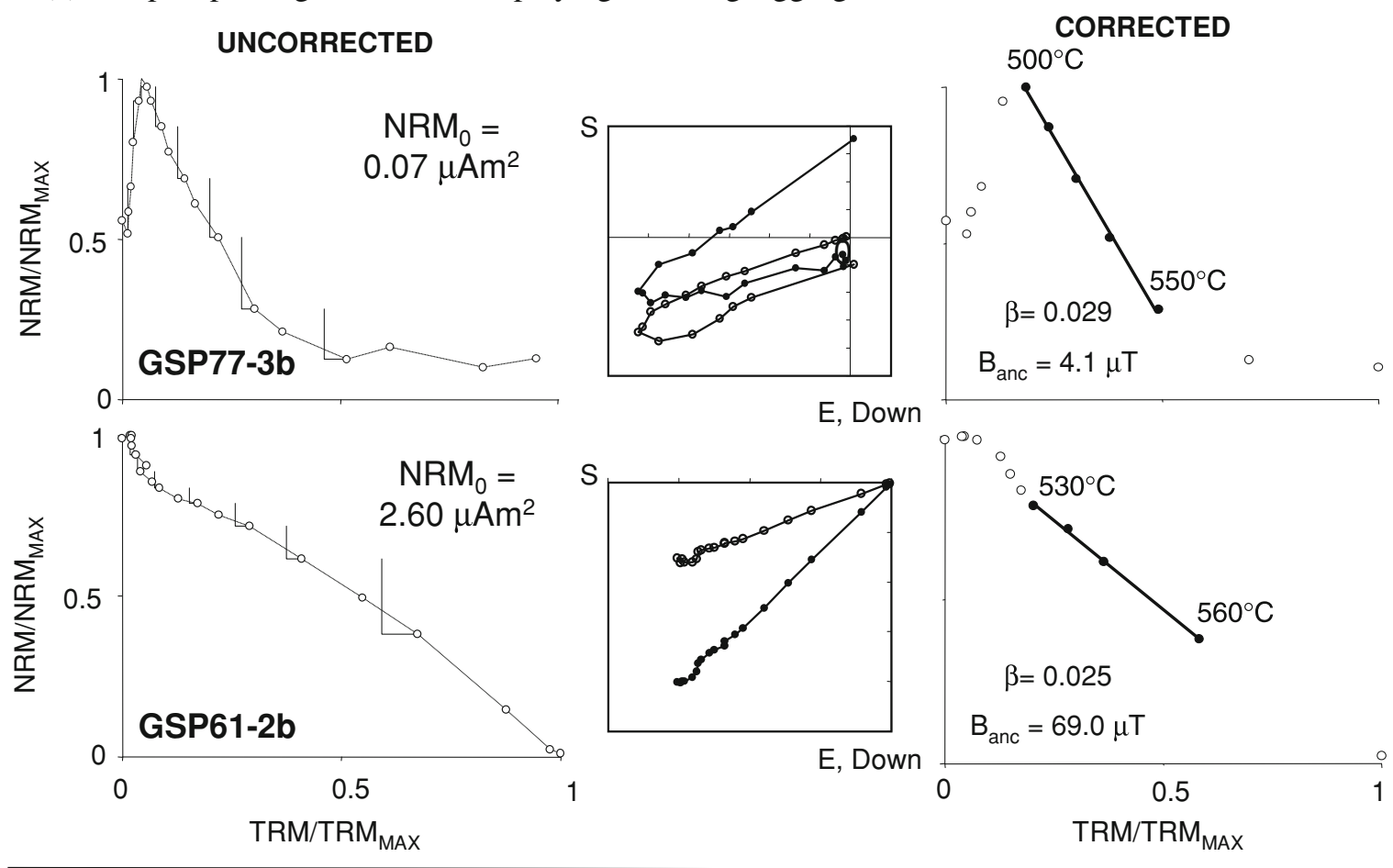

(d) Samples passing criteria and not displaying significant zigzagging behaviour
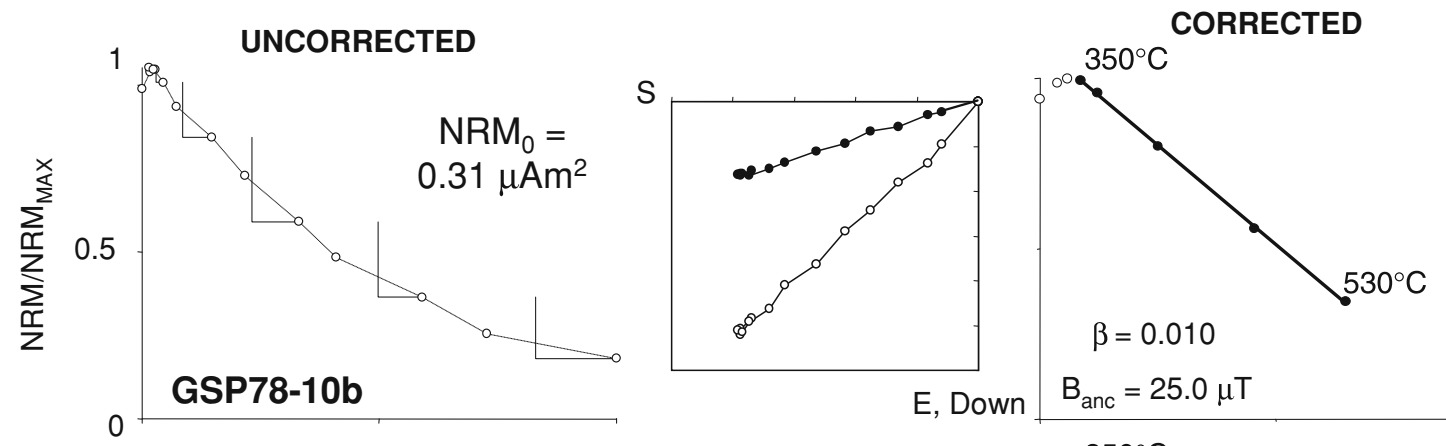

$$
\beta=0.010
$$$$
\mathrm{B}_{\mathrm{anc}}=25.0 \mu \mathrm{T}
$$
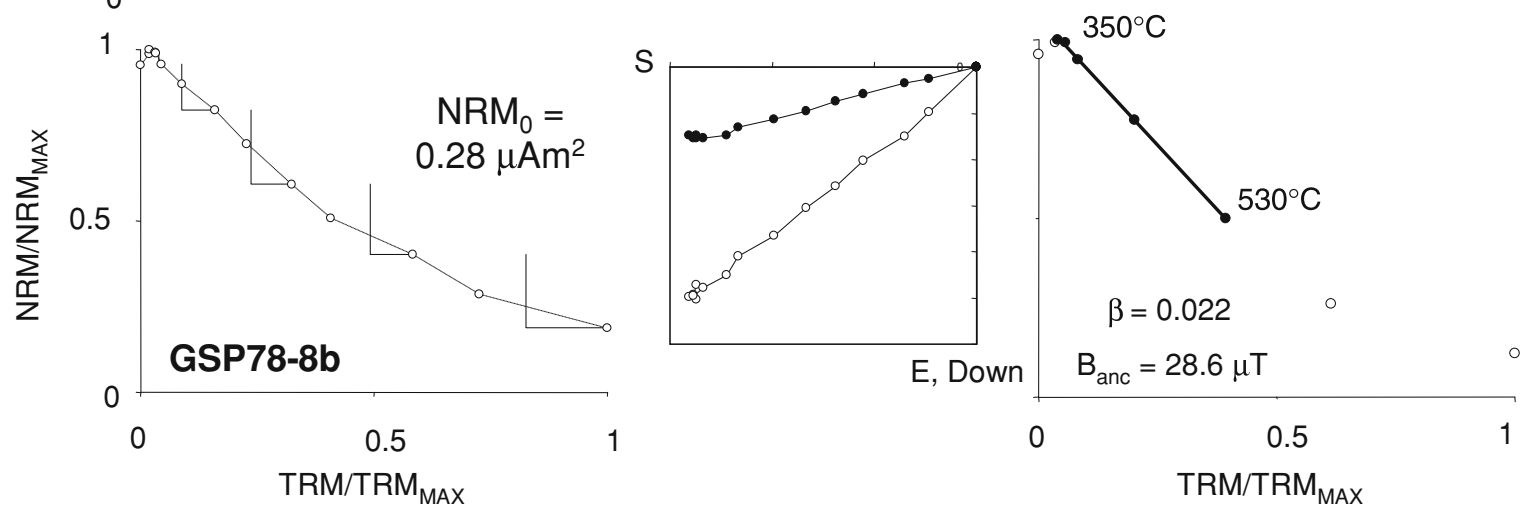

Fig. 5. (continued).

the demagnetisation; Tauxe and Staudigel, 2004) are expected to be far more affected by the imparting of CRM than points produced by ZI points. Consequently, even though the palaeointensity estimates were based on regression lines fit only to the ZI points on the Arai plots (because these were the only ones with pTRM and pTRM tail checks associated with them), both the ZI and the IZ points were used to ascertain the reliability of the estimate. Examples of Arai plots before and after correction for alteration, together with their associated Zijderveld plots are shown in Fig. 5.

A typical criterion in many palaeointensity studies is that the points on the Arai plot which are used to fit the regression line are sufficiently linear so that the standard error of the slope of the line divided by the slope itself (a ratio referred to as $\beta$ ) is 0.1 or less. The Arai plots of approximately half of the measured samples displayed much 
Table 2. Summary of alteration-corrected palaeointensity estimates which passed selection criteria described in the text $\left(\delta\left(t^{*}\right) \leq 3.0 ; \delta(T R) \leq 10.0\right.$; $\beta \leq 0.035)$ The site-mean palaeointensity determinations $\left(B_{\text {anc }}\right)$ and corresponding virtual dipole moments (VDM) are given with their standard deviation. $N$ is the number of consecutive points used to fit the regression line between $T_{\min }$ and $T_{\max }$. For explanation of the $f$ (fraction), $g$ (gap) and $q$ (quality) factors, see Coe et al. (1978) The maximum angular deviation (MAD) and difference angle (DANG) refer to the Zijderveld plots (Selkin et al., 2000); $\delta\left(t^{*}\right)$ and $\delta(T R)$ relate to the pTRM tail check and are described in the text. *These samples displayed significant (but not severe) zigzagging in their precorrected Arai plots and/or Zijderveld plots (see Fig. 5(c) for examples) and are therefore less reliable. ${ }^{\dagger}$ This value of $\delta\left(t^{*}\right)$ was permitted to exceed the threshold (3.0) on account of the otherwise high technical quality of this estimate.

\begin{tabular}{|c|c|c|c|c|c|c|c|c|c|c|c|c|c|c|}
\hline Sample & $\mathrm{T}_{\min }\left({ }^{\circ} \mathrm{C}\right)$ & $\mathrm{T}_{\max }\left({ }^{\circ} \mathrm{C}\right)$ & $\mathrm{N}$ & $\beta$ & $f$ & $\mathrm{~g}$ & $q$ & $\mathrm{MAD}^{\circ}$ & DANG $^{\circ}$ & $\delta\left(t^{\star}\right)$ & $\delta(\mathrm{TR})$ & \multicolumn{2}{|c|}{$\mathrm{B}_{\text {anc }}(\mu \mathrm{T})$} & $\operatorname{VDM}\left(\mathrm{ZAm}^{2}\right)$ \\
\hline GSP61.1b* & 350 & 550 & 7 & 0.022 & 0.41 & 0.81 & 15.0 & 4.2 & 1.7 & 2.8 & 4.9 & 32 & & \\
\hline GSP61.2b* & 530 & 560 & 4 & 0.025 & 0.40 & 0.58 & 9.2 & 1.2 & 0.2 & 2.2 & 4.0 & 69 & $40+24(60 \%)$ & \\
\hline GSP61.3b & 450 & 560 & 7 & 0.015 & 0.69 & 0.76 & 59.4 & 1.7 & 0.1 & $3.4^{\dagger}$ & 4.7 & 46 & $(60 \%)$ & 38 \\
\hline GSP61.4b* & 450 & 560 & 6 & 0.014 & 0.40 & 0.60 & 17.4 & 1.9 & 0.9 & 2.7 & 4.1 & 12 & & \\
\hline GSP77.3b* & 500 & 550 & 5 & 0.029 & 0.50 & 0.73 & 12.5 & 8.6 & 8.1 & 0.2 & 2.4 & 4 & 7 & \\
\hline GSP77.4b* & 350 & 540 & 6 & 0.028 & 0.20 & 0.77 & 5.3 & 4.5 & 1.3 & 0.6 & 1.0 & 9 & 7 & 11 \\
\hline GSP78.3b* & 300 & 520 & 5 & 0.016 & 0.47 & 0.58 & 17.0 & 2.7 & 0.8 & 2.8 & 2.9 & 34 & & \\
\hline GSP78.8b & 350 & 530 & 5 & 0.022 & 0.55 & 0.68 & 16.7 & 1.6 & 0.5 & 1.7 & 2.3 & 29 & $30+4(12 \%)$ & $47+6$ \\
\hline GSP78.10b & 350 & 530 & 5 & 0.010 & 0.59 & 0.69 & 39.6 & 1.0 & 0.6 & 2.1 & 2.9 & 25 & $30 \pm 4(12 \%)$ & $47 \pm 0$ \\
\hline GSP78.11b & 450 & 530 & 4 & 0.032 & 0.61 & 0.65 & 12.3 & 1.4 & 1.1 & 1.4 & 2.8 & 31 & & \\
\hline
\end{tabular}

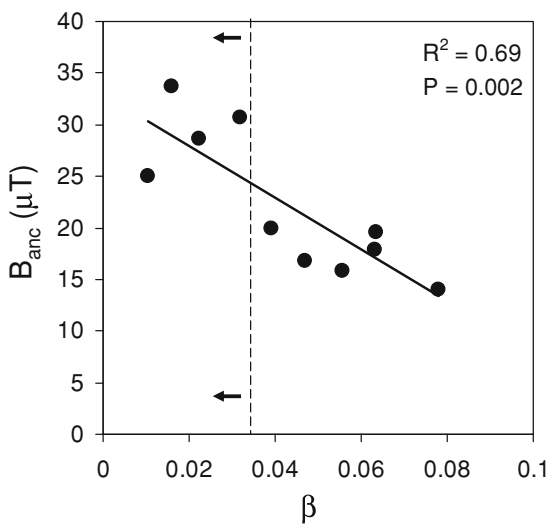

Fig. 6. Palaeointensity measurements made from samples from lava GSP78 plotted against their associated $\beta$ parameters (a measure of corrected Arai plot nonlinearity—see text). The samples producing less linear Arai plots gave lower results so consequently we applied a criterion requiring $\beta \leq 0.035$ (shown as dashed line) to all of our results. The $R^{2}$ value and the probability of no correlation are given.

improved linearity after the correction was applied so that they would pass this criterion. The alteration correction was especially effective when applied to results from the flow GSP78 making ten of the eleven measured samples produce linear Arai plots according to this criterion. However, there is a clear dependency of these palaeointensity estimates on the associated value of $\beta$ (Fig. 6) which suggests that those with $\beta$ values greater than 0.04 were biased to low values by uncorrected alteration. This finding was further supported by the observation that several of those estimates with higher $\beta$ values displayed some zigzagging on the complete Arai and/or Zijderveld plot (e.g. Fig. 5(b)).

On this basis we decided to modify the criterion so that it required $\beta$ to be less than 0.035 . Some 10 samples from 3 lavas passed this strict criterion (as well as the pTRM tail check criteria described above) and the statistical details of their palaeointensity estimates are provided in Table 2. It was only necessary to apply formal selection criteria to the parameters $\beta, \delta\left(t^{*}\right)$, and $\delta(T R)$; other parameters associated with the estimates that satisfied these would already satisfy most arbitrary criteria set by other studies. Despite their good technical quality however, the reliability of the mean determinations from the GSP61 and GSP77 lavas is still in some doubt for two reasons. The first is that these both comprise estimates from samples which display some zigzagging in their precorrected Arai and/or Zijderveld plot (see examples in Fig. 5(c)) which might indicate the occurrence of CRM formation, a type of alteration which cannot be corrected for (although some zigzagging is expected in the Arai plots from the 'correctable' type of alteration also). The second is that GSP61 displays a very high degree of within-site variation in the palaeointensity while GSP77 yields too few estimates to gauge the within-site variation. The site mean palaeointensity of lava GSP78 is based on four estimates which is insufficient to produce a truly reliable mean determination (Biggin et al., 2003); furthermore, the alteration-correction employed to obtain these is not universally accepted as reliable. Nonetheless, the high degree of consistency between the estimates is encouraging as is the low level of zigzagging in their precorrected plots (e.g. Fig. 5(d)). We therefore use its virtual dipole moment (VDM) estimate (which is $60 \%$ of today's value) in our analysis described in the next section and discuss its reliability further in Section 6.

\section{Long Term Trends in Geomagnetic Intensity Since the Archaean}

The IAGA absolute palaeointensity database has undergone numerous stages of updating (Tanaka and Kono, 1994; Perrin and Shcherbakov, 1997; Perrin and Schnepp, 2004; Tauxe and Yamazaki, 2007). We combined our single new data point with others from the most recent version (PINT08) which is available for download from the first author's homepage on: www.geo.uu.nl/fforth

It is always necessary to filter any palaeointensity database by applying quality criterion so as to remove the measurements which are most likely to be biased. Our selection criteria for the VDM/VADM determinations taken from PINT08 were:

1. Produced using the Thellier method incorporating pTRM checks - this method certainly does not guarantee that the determination is accurate (Biggin and Thomas, 2003a, b) but it does reduce the likelihood of it being biased by alteration. For this reason, microwave determinations were also retained.

2. A site mean determination produced from at least 3 


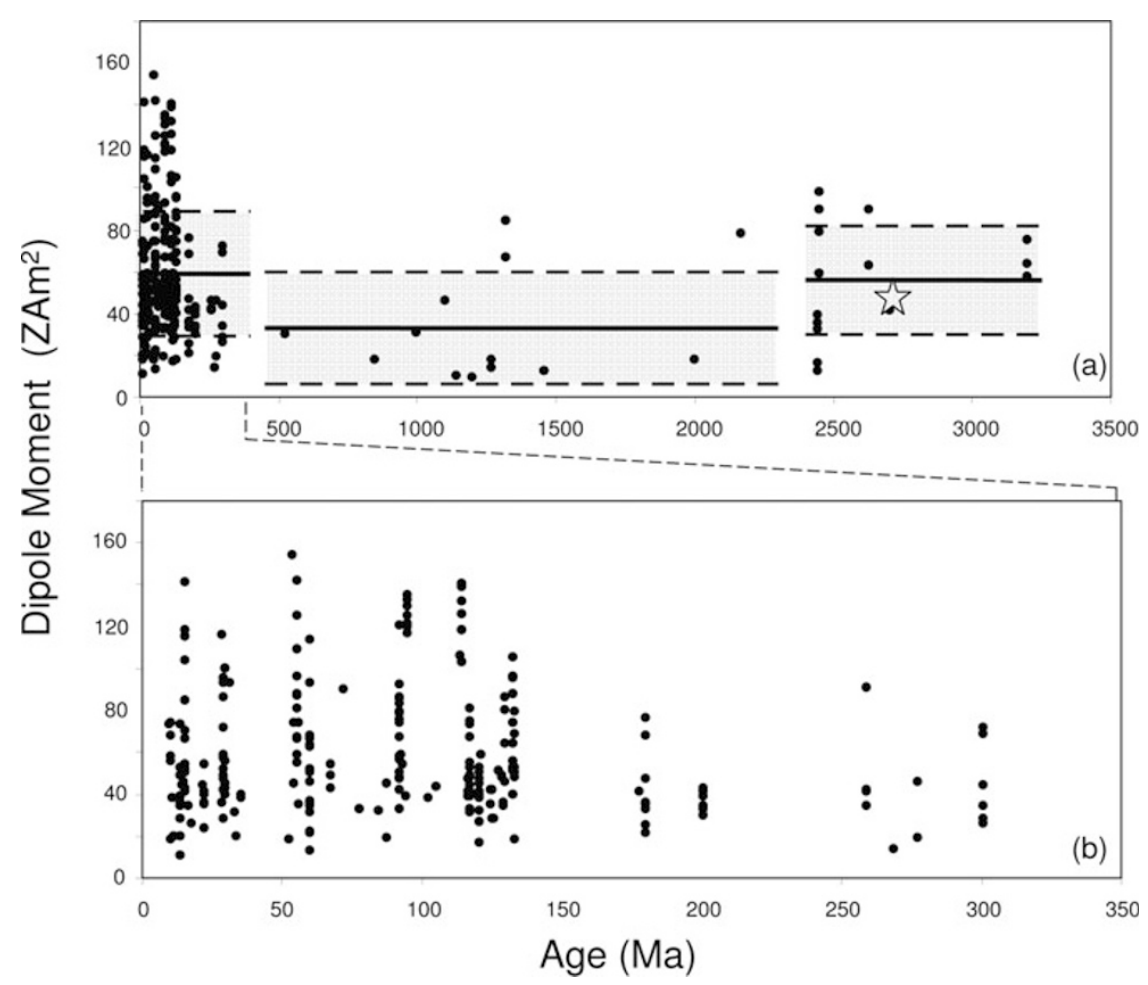

Fig. 7. Plots of V(A)DM versus age for (a) the entire 10-3200 Ma dataset and (b) the 10-301 Ma dataset. The GSP78 determination is shown as a star and the tentative 3 -stage model defined in the text is shown (mean \pm 1 standard deviation) as grey boxes.

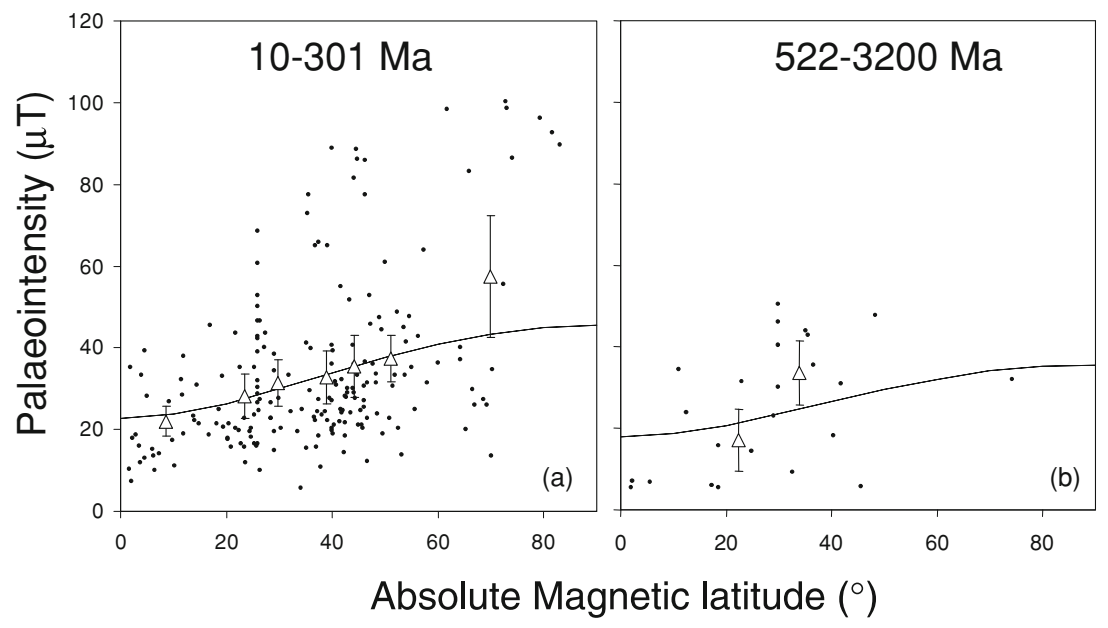

Fig. 8. Field intensity versus absolute magnetic latitude for the 10-301 Ma and the older dataset. Filled points are individual determinations, unfilled triangles are averages from bins which each contained 30 determinations in (a) (19 in highest latitude bin) and 12 determinations in (b). Error bars are $95 \%$ uncertainty bounds for the mean. The line indicates the field expected for a dipole with moment given by the total averages-(10-301 Ma-59 ZAm ${ }^{2}$; 522-3200 Ma-46 ZAm²).

individual measurements.

3. A standard deviation not greater than $25 \%$ of the mean-note that we do not automatically accept palaeointensity measurements with standard deviations less than $5 \mu \mathrm{T}$ as do some studies (e.g. Granot et al., 2007) because we argue that this is overly lenient to determinations with a low mean.

To allow us to concentrate on long timescale variations in the mean dipole moment we considered only determinations with an age $>10 \mathrm{Ma}$ and which were not recorded as being related to a reversal transition. Our resulting dataset of $271 \mathrm{~V}(\mathrm{~A}) \mathrm{DM}$ measurements is plotted against the associated age determination in Fig. 7(a). There are very large gaps in the record and the data are heavily concentrated in the period 10-301 Ma. Figure 7(b) shows that this recent period itself could be split into two sections: a poorly represented section of potentially lower dipole moment prior to $150 \mathrm{Ma}$ and a better represented section after this time. However, since the focus of the present study is on very long timescale variations in field intensity, we decided to leave it intact. The 10-301 Ma period is likely to be sufficiently long and well-represented to reasonably average out both secular variation and any longer timescale variations 


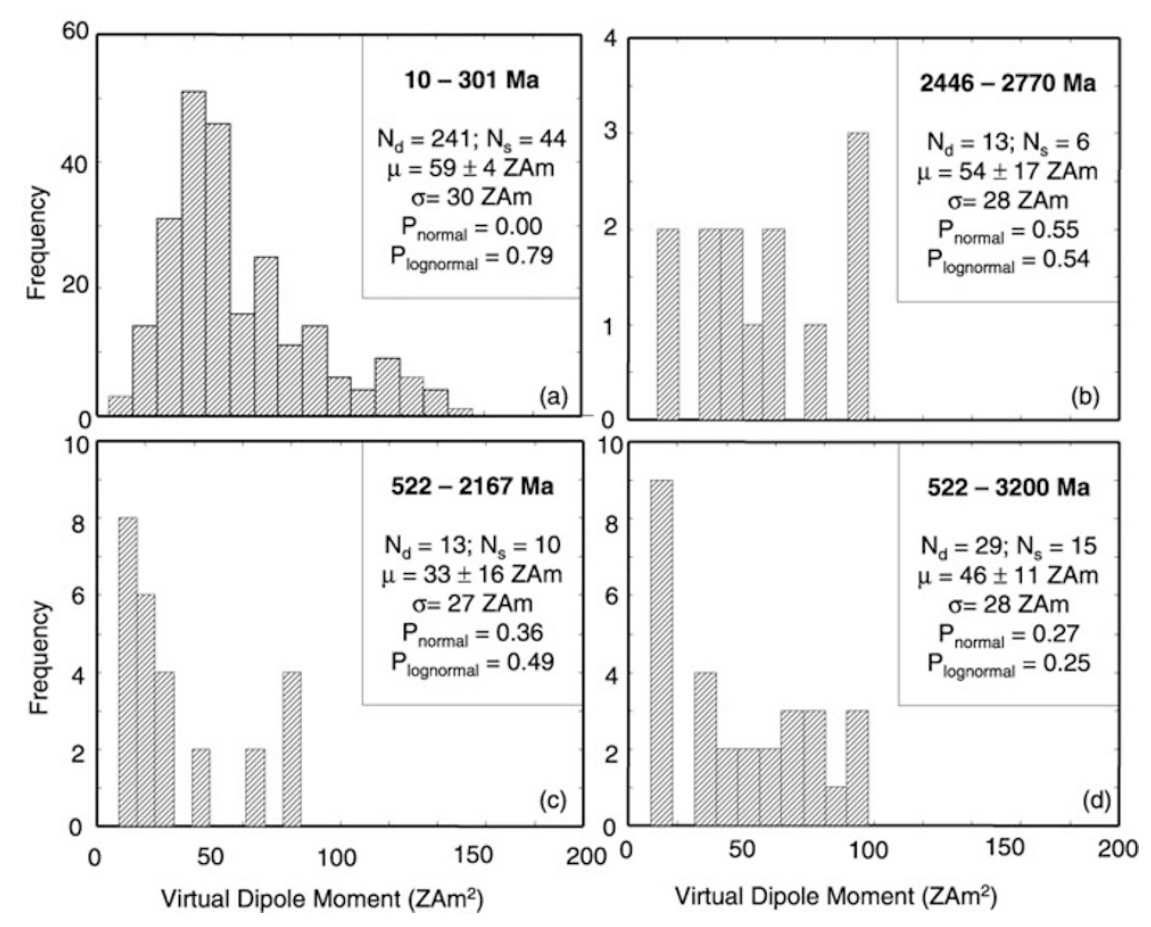

Fig. 9. Histograms of virtual (axial) dipole moments measured in four different time periods and associated statistical parameters. $N_{\mathrm{d}}$ and $N_{\mathrm{s}}$ refer to the the number of determinations and number of studies respectively. $\mu$ is the mean VDM with $95 \%$ confidence limits and $\sigma$ is the standard deviation. $P_{\text {normal }}$ and $P_{\text {lognormal }}$ are the probabilities, as defined by the Jarque-Bera test, of the data having been drawn from a normal and a log-normal distribution respectively.

forced by mantle convection. We tested this by assessing the fit of the palaeointensity data in this time window to the intensity-latitude relationship predicted by the dipole formula (Fig. 8). With the exception of the high latitude data (dominated by data from the Cretaceous Normal Superchron, Tarduno et al., 2002), the means of the binned data fit this relationship extraordinarily well. This suggests that our 10-301 Ma dataset is a reasonable first-order description of the time-averaged intensity of the field for this period which is not strongly biased by over-representation of extremes of either secular variation or mantle-forced variations (except at high latitudes). The mean intensity for this period $\left(59 \pm 4 \mathrm{ZAm}^{2}\right)$ is some $22 \%$ higher than that $\left(46 \pm 3 \mathrm{ZAm}^{2}\right)$ previously reported for a similar period $0.3-$ 300 Ma by Selkin and Tauxe (2000).

We wished to perform an equivalent analysis to that undertaken by Biggin et al. (2008) using palaeointensity data instead of palaeosecular variation data. We therefore merged our single reliable VDM determination with others from the period 2.44-2.80 Ga (Table 3). Overall, we have just 13 determinations of the dipole moment from 6 studies (5 independent recorders) to combine and compare against the set of 241 data with ages in the range 10-301 Ma. In this way, we compare the distribution of absolute palaeointensity determinations from two periods of time which are each long enough to average out mantle-derived variations and which are separated by a period of time likely to be sufficiently long to have allowed significant inner core growth (Labrosse et al., 2001).

Figure 9 shows that the 2446-2721 Ma VDM dataset could represent a random sample from either a normal or a lognormal distribution. The 10-301 Ma dataset on the other-hand is much more likely lognormal though it has similar parameters (mean and standard deviation) to those of the 2446-2721 Ma dataset (Fig. 9(a)). The KolmogorovSmirnov test (KS test, Selkin and Tauxe, 2000) was used to provide a test for the two datasets having been drawn from statistically-distinct distributions. The resulting $P$ value was rather high (0.95), which indicates that their distributions are entirely indistinguishable.

A robust palaeointensity dataset should comprise data from a sufficient number of independent studies to ensure that it is not heavily biased by any single set of bad measurements. We tested the stability of the 2446-2721 Ma dataset in this respect by iteratively excluding all data from each individual recorder while retaining data from the other four. This had the effect of modifying the mean from its overall value of $54 \mathrm{ZAm}^{2}$ to a minimum of 42 and a maximum of $71 \mathrm{ZAm}^{2}$. However, in both cases, the distribution of the reduced 2446-2721 Ma dataset was still not statistically distinguishable from that of the 10-301 Ma dataset.

The 2446-2721 Ma dataset is far too small to be sure of adequately representing the VDM distribution in this period. Nonetheless, our comparison analysis does not provide evidence for a fundamental change in average poloidal field intensity to match the change observed in directional secular variation by Biggin et al. (2008). The essence of this finding is similar to that reported by Dunlop and Yu (2004) who observed that most of the Precambrian estimates they defined as moderate-quality were within a range of not more than $50 \%$ higher or lower than the Phanerozoic average. However, it runs contrary to the findings of Macouin et al. (2004) who claimed the palaeointensity database displayed evidence for a long-term increase in the mean dipole mo- 
Table 3. Compilation of absolute palaeointensity data available for the period 2.45 to 2.80 Ga. *Quoted uncertainties in this table are $1 \sigma$. † Alteration-corrected result.

\begin{tabular}{|c|c|c|c|c|c|}
\hline Age (Ma) & Name & $\mathrm{N}$ & $\operatorname{VDM}\left(\mathrm{ZAm}^{2}\right)^{*}$ & $\sigma / \mu$ & Reference \\
\hline 2446 & Matachewan & 4 & $12 \pm 2$ & $18 \%$ & Halls et al. (2004) \\
\hline 2446 & Matachewan & 3 & $36 \pm 8$ & $23 \%$ & Halls et al. (2004) \\
\hline 2446 & Matachewan & 3 & $16 \pm 2$ & $10 \%$ & Macouin et al. (2003) \\
\hline 2446 & Matachewan & 5 & $32 \pm 8$ & $25 \%$ & Macouin et al. (2003) \\
\hline 2446 & Matachewan & 8 & $39 \pm 7$ & $18 \%$ & Macouin et al. (2003) \\
\hline 2449 & Karelia & 3 & $59 \pm 6$ & $10 \%$ & Smirnov et al. (2003) \\
\hline 2449 & Karelia & 4 & $79 \pm 15$ & $19 \%$ & Smirnov et al. (2003) \\
\hline 2449 & Karelia & 4 & $90 \pm 14$ & $15 \%$ & Smirnov et al. (2003) \\
\hline 2449 & Karelia & 4 & $98 \pm 22$ & $22 \%$ & Smirnov et al. (2003) \\
\hline 2631 & Slave & 9 & $63 \pm 3$ & $4 \%$ & Yoshihara \& Hamano (2000) \\
\hline 2631 & Slave & 6 & $90 \pm 3$ & $3 \%$ & Yoshihara \& Hamano (2000) \\
\hline 2703 & Stillwater & 3 & $41 \pm 7$ & $18 \%$ & Selkin et al. (2000) \\
\hline 2721 & Pilbara $^{\dagger}$ & 3 & $47 \pm 6$ & $12 \%$ & This study \\
\hline
\end{tabular}

ment. Part of the explanation for this disagreement is that Macouin et al. (2004) did not apply our criteria 2 and 3 to any of their data with ages $>300 \mathrm{Ma}$. If we neglect these criteria in our study then the mean of the 2446-2721 Ma dataset falls by $30 \%$ which is potentially due to the inclusion of less reliable data.

Another reason for the disagreement is the difference in the choice of age bins which were used to make the comparisons. Macouin et al. (2004) compared data from the last 300 Myr with data in two time windows in the period 800 3000 Ma. Published palaeointensity data with ages intermediate between the two periods compared by the present study (i.e. in the range 302-2445 Ma) give generally low dipole moment measurements (Fig. 9(c)). The distribution of these is distinct from that of the 10-301 Ma data at the 99\% confidence level. Does this imply that mean poloidal field intensity went down in the early Proterozoic and then back up in the Phanerozoic? If so then the thermal evolution of the core might provide an appealing explanation for this behaviour (discussed in the next section). However, many more data are required to allow us to be confident in this observation. In Fig. 9(d) we show the distribution of all data with ages greater than $301 \mathrm{Ma}$. This is also distinct (with a significantly lower mean) from the 10-301 Ma distribution at the 95\% confidence level which could be taken to support a long term increase in dipole moment from the Precambrian to the Phanerozoic. However, we are reluctant to claim even this based on the present state of the database. Specifically, we argue that the fit of a binned dataset to the dipole curve on a palaeointensitypalaeolatitude plot provides a good test of whether it contains a sufficiently large number of well-distributed determinations to produce a mean that is free from biasing by shorter timescale variations and random errors. Unfortunately, while the 10-301 Ma dataset appears to pass this test, the 522-3200 Ma dataset clearly fails it (Fig. 8(b)) which suggests that many more palaeointensity determinations of Precambrian age are necessary to obtain a robust mean for the period.

\section{Discussion}

We have performed detailed absolute palaeointensity experiments on extrusive rocks of late Archaean age. The samples faithfully record the direction of the palaeomag- netic field but, in spite of our pre-selection based on the results from thermomagnetic analysis, the results of the palaeointensity experiments were severely affected by alteration caused by the laboratory heating. Fortunately, an established method of correction for this alteration was extremely successful at improving the technical quality of the results. This correction is not without risk: alteration affecting remanence carriers with blocking temperatures higher than the temperature of the relevant pTRM check is not corrected for and therefore may still bias the determination. We guarded against this risk by applying strict selection criteria with respect to the linearity of the corrected Arai plot and the pTRM tail check discrepancies, and by looking for zigzagging in the pre-corrected Arai and Zijderveld plots. Even then, two of the three determinations may not be considered reliable, one (GSP61) on account of its poor internal consistency and another (GSP77) because it comprises just two estimates and is derived from a lava flow which gives poorly clustered directions of magnetisation (Table 1). Nonetheless, the single determination we present as reliable (GSP78) is badly needed; it increases the total number of such determinations available for the late Archaean-early Proterozoic by $8 \%$.

There are many potential factors which can bias a palaeointensity determination and ensuring that a result is unaffected by all of them can be far from trivial. The high technical quality of the (corrected) results allows us to be confident that the determination from lava GSP78 is unlikely to be strongly biased by magnetomineralogical alteration or multidomain effects. The potential for biasing caused by the remanence carriers undergoing chemical changes below their Curie temperature during the original cooling of the unit (and therefore retaining a chemical or thermochemical remanence) is, as for many studies, not so well constrained. The nature of such effects and the extent to which they occur is presently an area of active research (Smirnov and Tarduno, 2005; Draeger et al., 2006; Yamamoto, 2006). Here, we merely point out that the results of the rock magnetic analysis are consistent with the units having acquired a purely thermal remanence.

A remaining source of bias is the difference between the rates at which the samples were cooled through their blocking temperature in nature and in the laboratory. This effect can be strong enough to impart some bias even to results 
from samples from subaerial lavas (Biggin et al., 2007). Unfortunately, it is not possible to ascertain the magnitude of this bias on the results presented here (although we point out that it is unlikely to exceed a few tens of percent at most). This is primarily because the grains recording the remanence in these rocks are very unlikely to be in either the pure non-interacting single domain or pure multidomain state, and practically nothing is known about the cooling rate effect for grains lying between those extremes (in the flower, vortex, small multidomain, or interacting single domain states). Such grains are dominant in the vast majority of subaerial lavas so future work is badly needed to constrain the effect of cooling rate on TRM intensity in these.

If recent estimates of CMB heat flux are correct (Lay et al., 2006; van der Hilst et al., 2007), then for a period of at least 1.7 billion years before the inner core formed $(3.2 \mathrm{Ga}$ to $1.5 \mathrm{Ga}$, Tarduno et al., 2007), the geodynamo must have been powered purely by thermal convection. The greater retention of primordial heat in the core, potentially coupled with higher heat production from short-lived radioisotopes such as ${ }^{40} \mathrm{~K}$ (Buffett, 2003), may have driven thermal convection harder in the very early history of the Earth. If this was the case then it provides an appealing explanation for the pattern of fall and then rise in mean geomagnetic intensity which we tentatively propose based on the global dipole moment record (Fig. 7(a)). Specifically, the field may have been strong through the Archaean as the geodynamo was driven by vigorous thermal convection, it may then have became weaker as the thermal convection ebbed through the Proterozoic, and finally, it may have become re-established at higher values as compositional convection was initiated by inner core nucleation at some point in the late Proterozoic or Phanerozoic.

The existence of a Proterozoic dipole low (or even a Precambrian dipole low) remains far from certain given the current sparse status of the palaeointensity database. Figure 7 indicates numerous long periods throughout the Earth's history for which reliable palaeointensity data are sparse or entirely absent. The filling of these gaps by future palaeointensity studies will undoubtedly play a major role in elucidating the thermodynamic evolution of the core.

\section{Conclusions}

1. A previously published method of correcting for magnetomineralogical alteration induced in a Thellier-type palaeointensity experiment was very effective at increasing the technical quality of the measurements made here from late Archaean basalts from Western Australia. Nonetheless, we considered that the determination from just one single flow was reliable and this gave a dipole moment estimate of $\sim 60 \%$ of today's value.

2. An analysis of the PINT08 database showed that, for the period 10-301 $\mathrm{Ma}$, the number of data in every palaeolatitude bin except $> \pm 60^{\circ}$ was sufficient to average secular variation, mantle-forced variations, and random errors so that their average palaeointensity fit a dipole relationship extremely well. Data from earlier periods are too sparse to satisfy this criterion which reduces our confidence in the inferred mean geomag- netic intensity during this time.

3. The caveat above notwithstanding, our analysis of the PINT08 database has produced the intriguing suggestion that field intensity was high in the Archaeanearliest Proterozoic, low in the Proterozoic, and became higher again some time between the late Proterozoic and mid-Phanerozoic. If this pattern of dipole moment behaviour is substantiated by the addition of good quality data in the future, then it could indicate an associated three-stage evolution of core dynamics.

Acknowledgments. The work of GS was conducted under the programme of the Vening Meinesz Research School of Geodynamics (VMSG). We are grateful to Prof Lisa Tauxe for allowing GS access to equipment at the palaeomagnetic lab at Scripps Institute of Oceanography, for helping to update the PINT08 database, and for commenting on an earlier version of this manuscript. We are also grateful to Miriam Gómez-Paccard and an anonymous reviewer for their detailed comments. Thanks also to Tom Mullender for helping with the separation of the ferri- and paramagnetic components in the thermomagnetic curves. AJB acknowledges funding from the Netherlands Science Foundation (NWO) and his good fortune in working, for a short time in his career, at Montpellier with Michel Prévot: an inspiration to all those concerned with the measurement of palaeointensity.

\section{References}

Biggin, A. J. and D. N. Thomas, Analysis of long-term variations in the geomagnetic poloidal field intensity and evaluation of their relationship with global geodynamics, Geophys. J. Int., 152(2), 392-415, 2003 a.

Biggin, A. J. and D. N. Thomas, The application of acceptance criteria to results of Thellier palaeointensity experiments performed on samples with pseudo-single-domain-like characteristics, Phys. Earth Planet. Inter., 138(3-4), 279-287, 2003b.

Biggin, A. J., H. N. Böhnel, and F. R. Zuniga, How many paleointensity determinations are required from a single lava flow to constitute a reliable average?, Geophys. Res. Lett., 30(11), 10.1029/2003GL017146, 2003.

Biggin, A. J., M. Perrin, and M. J. Dekkers, A reliable palaeointensity determinations obtained from a non-ideal recorder, Earth Planet. Sci. Lett., 257, 545-563, 2007.

Biggin, A. J., G. Strik, and C. G. Langereis, Evidence for a very long term trend in geomagnetic secular variation, Nature Geosci., 1(6), 395-398, 2008.

Blake, T. S., Late Archean Crustal Extension, Sedimentary Basin Formation, Flood-Basalt Volcanism and Continental Rifting - the Nullagine and Mount Jope Supersequences, Western-Australia, Precambrian Res., 60(1-4), 185-241, 1993.

Blake, T. S., Cyclic continental mafic tuff and flood basalt volcanism in the Late Archaean Nullagine and Mount Jope-Supersequences in the eastern Pilbara, Western Australia, Precambrian Res., 107(3-4), 139177, 2001.

Blake, T. S., A new regional stratigraphic framework for the lower succession of the Hammersley Province on the northern Pilbara Craton, Western Australia, (in prep.).

Blake, T. S., R. Buick, S. J. A. Brown, and M. E. Barley, Geochronology of a Late Archaean flood basalt province in the Pilbara Craton, Australia: constraints on basin evolution, volcanic and sedimentary accumulation, and continental drift rates, Precambrian Res., 133(3-4), 143-173, 2004.

Buffett, B. A., The thermal state of Earth's core, Science, 299(5613), 16751677, 2003.

Coe, R. S. and G. A. Glatzmaier, Symmetry and stability of the geomagnetic field, Geophys. Res. Lett., 33(21), 2006GL027903, 2006.

Coe, R. S., C. S. Grommé, and E. A. Mankinen, Geomagnetic paleointensities from radiocarbon dated lava flows on Hawaii and the question of the Pacific non-dipole low, J. Geophys. Res. (Solid Earth), 83, 1740-1756, 1978.

Cottrell, R. D. and J. A. Tarduno, In search of high-fidelity geomagnetic paleointensities: A comparison of single plagioclase crystal and whole rock Thellier-Thellier analyses, J. Geophys. Res. (Solid Earth), 105(B10), 23579-23594, 2000. 
Courtillot, V. and P. Olson, Mantle plumes link magnetic superchrons to Phanerozoic mass depletion events, Earth Planet. Sci. Lett., 260, 495504, 2007.

Draeger, U., M. Prevot, T. Poidras, and J. Riisager, Single-domain chemical, thermochemical and thermal remanences in a basaltic rock, Geophys. J. Int., 166(1), 12-32, 2006.

Dunlop, D. J. and Y. Yu, Intensity and polarity of the geomagnetic field during Precambrian time, in Timescales of the Internal Geomagnetic Field, edited by J. E. T. Channell, 85-100, Geophysical monograph series. AGU, Washington DC, 2004.

Granot, R., L. Tauxe, J. S. Gee, and H. Ron, A view into the Cretaceous geomagnetic field from analysis of gabbros and submarine glasses, Earth Planet. Sci. Lett., 256(1-2), 1-11, 2007.

Gubbins, D., D. Alfe, G. Masters, G. D. Price, and M. J. Gillan, Can the Earth's dynamo run on heat alone?, Geophys. J. Int., 155(2), 609-622, 2003.

Halls, H. C., N. J. McArdle, M. N. Gratton, M. J. Hill, and J. Shaw, Microwave paleointensities from dyke chilled margins: a way to obtain long-term variations in geodynamo intensity for the last three billion years, Phys. Earth Planet. Inter., 147(2-3), 183-195, 2004.

Kirschvink, J. L., The least-squares line and plane and the analysis of palaeomagnetic data, Geophys. J. R. Astron. Soc., 62, 699-718, 1980.

Labrosse, S., Thermal and magnetic evolution of the Earth's core, Phys. Earth Planet. Inter., 140(1-3), 127-143, 2003.

Labrosse, S., J. P. Poirier, and J. L. Le Mouel, The age of the inner core, Earth Planet. Sci. Lett., 190(3-4), 111-123, 2001.

Lay, T., J. Hernlund, E. J. Garnero, and M. S. Thorne, A post-perovskite lens and $\mathrm{D}^{\prime \prime}$ heat flux beneath the central Pacific, Science, 314(5803), 1272-1276, 2006.

Leonhardt, R., C. Heunemann, and D. Krasa, Analyzing absolute paleointensity determinations: Acceptance criteria and the software ThellierTool4.0, Geochem. Geophys. Geosyst., 5, doi:10.1029/2004GC000807, 2004

Macouin, M. et al., Low paleointensities recorded in 1 to 2.4 Ga Proterozoic dykes, Superior Province, Canada, Earth Planet. Sci. Lett., 213(12), 79-95, 2003

Macouin, M., J. P. Valet, and J. Besse, Long-term evolution of the geomagnetic dipole moment, Phys. Earth Planet. Inter., 147(2-3), 239246, 2004.

McClelland, E. and J. C. Briden, An improved methodology for Thelliertype paleointensity determination in igneous rocks and its usefulness for verifying primary thermoremanence, J. Geophys. Res. (Solid Earth), 101(B10), 21995-22013, 1996.

Mullender, T. A. T., A. J. Vanvelzen, and M. J. Dekkers, Continuous Drift Correction and Separate Identification of Ferrimagnetic and Paramagnetic Contributions in Thermomagnetic Runs, Geophys. J. Int., 114(3), 663-672, 1993.

Nagata, T., Y. Arai, and K. Momose, Secular variation of the geomagnetic total force during the last 5000 years, J. Geophys. Res., 68, 5277-5282, 1963.

Perrin, M. and V. Shcherbakov, Paleointensity of the earth's magnetic field for the past $400 \mathrm{Ma}$ : Evidence for a dipole structure during the Mesozoic Low, J. Geomag. Geoelectr., 49(4), 601-614, 1997.

Perrin, M. and E. Schnepp, IAGA paleointensity database: distribution and quality of the data set, Phys. Earth Planet. Inter., 147(2-3), 255-267, 2004.

Prévot, M. and M. Perrin, Intensity of the Earths Magnetic-Field since Precambrian from Thellier-Type Paleointensity Data and Inferences on the Thermal History of the Core, Geophys. J. Int., 108(2), 613-620, 1992.

Riisager, P. and J. Riisager, Detecting multidomain magnetic grains in Thellier palaeointensity experiments, Phys. Earth Planet. Inter., 125(14), 111-117, 2001

Roberts, N. and J. D. A. Piper, A description of the behaviour of the Earth's magnetic field, in Geomagetism, edited by J. A. Jacobs, pp. 163-260, Elsevier, New York, 1989.

Roberts, P. H. and G. A. Glatzmaier, The geodynamo, past, present and future, Geophys. Astrophys. Fluid Dynamics, 94(1-2), 47-84, 2001

Selkin, P. A. and L. Tauxe, Long-term variations in palaeointensity, Philos. Trans. R. Soc. London Ser. Math. Phys. Eng. Sci., 358(1768), 1065$1088,2000$.
Selkin, P. A., J. S. Gee, L. Tauxe, W. P. Meurer, and A. J. Newell, The effect of remanence anisotropy on paleointensity estimates: a case study from the Archean Stillwater Complex, Earth Planet. Sci. Lett., 183(34), 403-416, 2000.

Smirnov, A. V. and J. A. Tarduno, Secular variation of the Late Archean Early Proterozoic geodynamo, Geophys. Res. Lett., 31(16), 10. 1029/2004GL020333, 2004

Smirnov, A. V. and J. A. Tarduno, Thermochemical remanent magnetization in Precambrian rocks: Are we sure the geomagnetic field was weak?, J. Geophys. Res. (Solid Earth), 110(B6), 2005.

Smirnov, A. V., J. A. Tarduno, and B. N. Pisakin, Paleointensity of the early geodynamo $(2.45 \mathrm{Ga})$ as recorded in Karelia: A single-crystal approach Geol., 31(5), 415-418, 2003.

Smith, R. E., J. L. Perdrix, and T. C. Parks, Burial metamorphism in the Hamersley Basin, Western Australia, J. Petrol., 23, 75-102, 1982.

Strik, G., M. J. de Wit, and C. G. Langereis, Palaeomagnetism of the Neoarchaean Pongola and Ventersdorp Supergroups and an appraisal of the 3.0-1.9 Ga apparent polar wander path of the Kaapvaal Craton, Southern Africa, Precambrian Res., 153(1-2), 96-115, 2007.

Strik, G. H. M. A., Palaeomagnetism of late Archaean flood basalt terrains: implications for early Earth geodynamics and geomagnetism, Geolog. Ultraiectina, 242, Utrecht, 160 pp., 2004.

Strik, G. H. M. A., T. S. Blake, T. E. Zegers, S. H. White, and C. G. Langereis, Palaeomagnetism of flood basalts in the Pilbara Craton, Western Australia: Late Archaean continental drift and the oldest known reversal of the geomagnetic field, J. Geophys. Res. (Solid Earth), 108(B12), EPM 2-1-EPM 2-21, 2003.

Tanaka, H. and M. Kono, Paleointensity database provides new resource, Eos Trans. AGU, 75, 498, 1994

Tarduno, J. A., R. D. Cottrell, and A. V. Smirnov, The Cretaceous superchron geodynamo: Observations near the tangent cylinder, Proc. Natl. Acad. Sci. USA, 99(22), 14020-14025, 2002.

Tarduno, J. A., R. D. Cottrell, M. K. Watkeys, and D. Bauch, Geomagnetic field strength 3.2 billion years ago recorded by single silicate crystals, Nature, 446, 657-660, 2007.

Tauxe, L. and H. Staudigel, Strength of the geomagnetic field in the Cretaceous Normal Superchron: New data from submarine basaltic glass of the Troodos Ophiolite, Geochem. Geophys. Geosyst., 5, Q02H06, 2004.

Tauxe, L. and T. Yamazaki, Paleointensities, in Geomagnetism, Treatise on Geophysics, edited by M. Kono, pp. 510-563, Elsevier, Amsterdam, 2007.

Thellier, E., Sur l'aimantation des terres cuites et ses applications géophysique, Ann. Inst. Phys. Globe Univ. Paris, 16, 157-302, 1938.

Thellier, E. and O. Thellier, Sur l'intensité du champ magnétique terrestre dans la passé historique et géologique, Ann. Géophys., 15, 285-376, 1959.

Valet, J. P. et al., Absolute paleointensity and magnetomineralogica changes, J. Geophys. Res. (Solid Earth), 101(B11), 25029-25044, 1996.

van der Hilst, R. D. et al., Seismostratigraphy and thermal structure of Earth's core-mantle boundary region, Science, 315(5820), 1813-1817, 2007.

Wingate, M. T. D., Ion microprobe baddeleyite and zircon ages for Late Archaean mafic dykes of the Pilbara Craton, Western Australia, Aust. J. Earth Sci., 46(4), 493-500, 1999.

Yamamoto, Y., Possible TCRM acquisition of the Kilauea 1960 lava, Hawaii: failure of the Thellier paleointensity determination inferred from equilibrium temperature of the Fe-Ti oxide, Earth Planets Space, 58(8), 1033-1044, 2006.

Yoshihara, A. and Y. Hamano, Intensity of the Earth's magnetic field in late Archean obtained from diabase dikes of the Slave Province, Canada, Phys. Earth Planet. Inter., 117(1-4), 295-307, 2000.

Zijderveld, J. D. A., Demagnetization in rocks: Analysis of results, in Methods in Palaeomagnetism, edited by S. K. Runcorn, pp. 254-286, Elsevier, New York, 1967.

A. J. Biggin (e-mail: biggin@geo.uu.nl), G. H. M. A. Strik, and C. G. Langereis 